\title{
Pathophysiological role of major adipokines in Atrial Fibrillation
}

Saira Rafaqat ${ }^{* *}$, Sana Rafaqat ${ }^{1}\left[0\right.$ and Simon Rafaqat $^{2}$

\begin{abstract}
Background: The adipokines, secreted from adipose tissue or body fats, are also called adipocytokines which are cytokines, cell signaling proteins or cell-cell communication. However, AF is a common cardiac arrhythmia in which the heart beats so fast by abnormal beating and is a serious public health disease associated with increased heart failure, systemic thromboembolism, and death. Adipokines are cardiovascular disease (CVD) mediators or biomarkers that affect the heart as well as blood vessels, by increasing the cardiac contractility and action potential duration, which result in the extent of left ventricular and atrial remodeling.

Main body: Google Scholar, PubMed, and science direct were used to review the literature. Many keywords were used for searching the literature such as Adipokines, Leptin, Apelin, Adiponectin, Omentin-1, Chemerin, CTRP3, TNF-a, IL-6, IL-10, and AF. According to the literature, much more data are available for numerous adipokines, but this review article only has taken few major adipokines which played their major role in Atrial Fibrillation. The review article did not limit the time frame.

Conclusion: In conclusion, adipokines play a significant role in the development and progress of atrial fibrillation. Also, there are major adipokines such as adiponectin, apelin, C1q/TNF-Related Protein 3 (CTRP3), Chemerin, Omentin-1, interleukin-6, Leptin, TNF-a, resistin, and interleukin-10, which played their pathophysiological role in atrial fibrillation by causing cardiac hypertrophy, increasing the cardiac contractility and action potential duration, atrial fibrosis, electrical and structural remodeling of atrial tissue.
\end{abstract}

Keywords: Adiponectin, Apelin, C1q/TNF-Related Protein 3, Chemerin, Omentin-1, Interleukin-6, Leptin, TNF-a, Resistin, Interleukin-10

\section{Background}

The adipokines, secreted from adipose tissue or body fats, are also called adipocytokines which are cytokines, cell signaling proteins or cell-cell communication. Leptin was the first adipokine that was discovered in 1994. Afterward, numerous adipokines have been discovered $[1,2]$. Adipokines are also known as a growth factor, hormones, cytokines as well as angiogenic factors. In addition, most studied adipokines include monocytes, leptin,

*Correspondence: saera.rafaqat@gmail.com

${ }^{1}$ Lahore College for Women University, Near Wapda Flats, Jail Rd, Jubilee Town, Lahore 54000, Punjab, Pakistan

Full list of author information is available at the end of the article interleukin-6 (IL-6), TNF, interleukin 1 beta (IL-1 $\beta$ ), adiponectin, interleukin-10 (IL-10), macrophage chemotactic protein-1, resistin, and transforming growth factor beta (TGF- $\beta$ ) $[3,4]$.

$\mathrm{AF}$ is a common cardiac arrhythmia in which the heart beats so fast by abnormal beating that is a serious public health disease and associated with increased heart failure, systemic thromboembolism, and death [5].

There are many aspects of AF pathophysiology involved in AF development including inflammatory factors, effects of the autonomic nervous system, atrial remodeling, and oxidative stress. Moreover, it increases the risk of morbidity, stroke, and disability. In the myocardium, structural and electrical remodeling is the primary cause 
of AF. Furthermore, atrial fibrosis is the excessive accumulation of extracellular matrix (ECM) in the atrium which is the trademark of structural remodeling. Also, several atrial fibrosis might cause paroxysmal AF to become permanent $\mathrm{AF}$ and even can reduce the effectiveness of antiarrhythmic therapy $[6,7]$.

Adipokines are produced from adipose tissues, which are considered endocrine organs involved in cardiovascular function causing electrophysiological effects such as ionic profiles, contractility in the atrium, and change in morphology of action potential. Also, adipokines are involved in cardioprotective effects including apelin, adiponectin, and omentin-1; however, adipokines that are involved in predisposing to cardiotoxicity are chemerin, resistin, and visfatin $[8,9]$.

In addition, adipokines are cardiovascular disease (CVD) mediators or biomarkers that affect the heart as well as blood vessels, by increasing the cardiac contractility and action potential duration, which result in the extent of left ventricular and atrial remodeling. In chronic AF, patients were found to have a higher level of adiponectin than the level of related collagen type 1 degradation marker. Moreover, atrial structural remodeling happens due to the activation of fibrosis as fibrotic scarring and fibroblasts $[10,11]$.

The current review article focuses on the basic role of few adipokines associated with Atrial Fibrillation. In particular, the role of pathophysiological pathways/ mechanisms of AF ultimately linked to adipokines. There are numerous adipokines; however, our review article emphases only on adiponectin, apelin, C1q/TNF-Related Protein 3 (CTRP3), Chemerin, Omentin-1, interleukin-6, Leptin, TNF- $\alpha$, resistin, interleukin-10 and their pathophysiological role in Atrial Fibrillation. Finally, we provide an outlook on the recent pathophysiological role of few adipokines in Atrial Fibrillation.

Google Scholar, PubMed, and science direct were used to review the literature. Many keywords were used for searching the literature such as Adipokines, Leptin, Apelin, Adiponectin, Omentin-1, Chemerin, CTRP3, TNF$\alpha$, IL-6, IL-10, and AF. According to the literature, much more data are available for numerous adipokines, but our study only has taken few major adipokines which played their major role in Atrial Fibrillation. Our review article did not limit the time frame.

\section{Main text}

There are many adipokines; however, this review article has discussed only major adipokines such as adiponectin, apelin, C1q/TNF-Related Protein 3 (CTRP3), Chemerin, Omentin-1, interleukin-6, Leptin, TNF- $\alpha$, resistin, interleukin-10, which played their pathophysiological role in Atrial Fibrillation as explained in Table 1.

\section{Adiponectin}

Adipose tissues, which are important adipokines as well as a protein hormone, that secrete adiponectin and also are encoded in humans on the ADIPOQ gene which is found in the liver, muscles, placenta in pregnant women, and brain. It prevents fat accumulation and regulates glucose [12-14]. Moreover, vasodilation, insulin sensitization, anti-atherogenesis, and lipid oxidation enrichment are few functions played by adiponectin. In kidneys, it plays a different role by preventing renal arteries from degradation, improving filtration, and reducing protein excretion range. Then, these functions are completed with the help of regulating anabolic pathways and renal tissues which reduce the oxidative stress level. It is a beneficial target for several metabolic diseases such as insulin resistance, oxidative stress, obesity, and hypertension. Furthermore, Adiponectin improves vascular function and avoids the progress of atherosclerosis, and also inflammatory processes are prevented [15-17].

According to the previous studies, it might be hypothesized that the link between AF and adiponectin could be age as well as gender-dependent. In addition, the most important pathogenetic factors are autonomic, atrial remodeling, and inflammation for atrial fibrillation [1820]. Zhu et al. (2021) also found that serum adiponectin was associated with the markers of cardiac autonomic, inflammation as well as cardiac remodeling. Moreover, subsequent multivariate analysis showed a significant independent link between elevated adiponectin levels and atrial fibrillation in the overall participants [21].

In addition, Kourliouros et al. also explained that a greater inflammation environment could provide a substrate for the development of arrhythmia. Also, elevated epicardial adipose tissue (EAT) levels of adiponectin are related to a lowered risk of developing postoperative atrial fibrillation in subjects undergoing cardiac surgery [22]. Additionally, Kusayama et al. study had revealed that inflammation of EAT around the left atrial has been associated with the presence of paroxysmal atrial fibrillation which had determined by elevated density in computed tomography images [23].

In atrial fibrillation-related structural remodeling, the predominant pathologic abnormality is the atrial fibrosis and also clinical significance has a degree of fibrosis. Epicardial fat is a metabolically active tissue that generates a variety of bioactive molecules including TNF- $\alpha$ and adiponectin which can be the key mediators of atrial fibrosis as well as structural remodeling [22, 24-27].

Bilovol et al. reported that adiponectin involvement in cardiac remodeling including direct action on the cardiac muscle, vascular inflammation, atherogenesis, and also the indirect action on the endothelial function. Adiponectin influences the functioning of the heart 
Table 1 Summary of pathophysiological aspects of major adipokines in Atrial Fibrillation

\begin{tabular}{|c|c|}
\hline Adipokines & Pathophysiological aspects in AF \\
\hline Adiponectin & $\begin{array}{l}\text { Involvement in cardiac remodeling } \\
\text { Atrial remodeling } \\
\text { Autonomic dysfunction and inflammation }\end{array}$ \\
\hline Apelin & $\begin{array}{l}\text { Influence atrial myocytes, } \\
\text { Shortening the action potential, } \\
\text { Increased mean arterial filling pressure and cardiac contractility, } \\
\text { Increase in the conduction velocity, } \\
\text { Decrease in the field potential duration, } \\
\text { Changing blood pressure, } \\
\text { Cardiac inotropy, oxidative stress, myocardial fibrosis, and hypertrophy }\end{array}$ \\
\hline CTRP3 & $\begin{array}{l}\text { Atrial fibrosis and structural remodeling } \\
\text { The thickness of the atrial septum } \\
\text { Myocardial remodeling }\end{array}$ \\
\hline Chemerin & $\begin{array}{l}\text { Arterial stiffness } \\
\text { Carotid artery plaque instability } \\
\text { Atrial remodeling }\end{array}$ \\
\hline Omentin-1 & $\begin{array}{l}\text { Atrial structural remodeling } \\
\text { Atrial fibrosis } \\
\text { Electrical atrial remodeling }\end{array}$ \\
\hline Interleukin-6 & $\begin{array}{l}\text { Modification of the cardiac extracellular matrix and cardiac dysfunction, } \\
\text { Affects cell-to-cell communication between cardiac myocytes and fibroblasts, } \\
\text { Development of myocardial damage } \\
\text { The severity of left ventricular dysfunction, } \\
\text { Left ventricular assist device conditions, } \\
\text { Rapidly induces atrial electrical remodeling }\end{array}$ \\
\hline Leptin & $\begin{array}{l}\text { Progress of atrial fibrosis and atrial fibrillation evoked by angiotensin II } \\
\text { Increased fibrosis, } \\
\text { Enhanced inflammation, } \\
\text { Promoting cardiac remodeling due to impaired cardiac metabolism, } \\
\text { Dysfunction of vascular } \\
\text { Ventricular hypertrophy } \\
\text { Increase in myocardial workload } \\
\text { Cardiac hypertrophy }\end{array}$ \\
\hline TNF-a & $\begin{array}{l}\text { Contributes to hypertension, } \\
\text { Vascular dysfunction, } \\
\text { Atherosclerosis progression, and cardiac remodeling } \\
\text { Lower the cardiac myocytes contraction, } \\
\text { The marker for hypertrophy, } \\
\text { Ventricular remodeling, } \\
\text { Cardiac allograft, } \\
\text { Atrial fibrosis, } \\
\text { Atrial structural remodeling, } \\
\text { Atrial electrical remodeling, } \\
\text { Abnormal } \mathrm{Ca}^{2+} \text { handling and intracellular } \mathrm{Ca}^{2+} \text { overload }\end{array}$ \\
\hline Resistin & $\begin{array}{l}\text { Chronic left ventricular myocardial damage resulting in left ventricular dysfunction } \\
\text { Fatty infiltration of the atrial wall }\end{array}$ \\
\hline Interleukin-10 & $\begin{array}{l}\text { Progress of widespread and unbalanced atherosclerotic lesions } \\
\text { A strong link between the risk of developing atrial fibrillation and IL-10-592A/C polymorphism }\end{array}$ \\
\hline
\end{tabular}

through central nervous system when adiponectin enters through the blood-brain barrier. Adipocytokine imbalance including a lower level of adiponectin which results in the development of hyperinsulinemia, dyslipidemia, endothelial dysfunction, fibrosis, abdominal obesity, arterial hypertension, impaired glucose tolerance, and atrial fibrillation [28]. Moreover, Macheret et al. reported the significant association between raised adiponectin levels and increased occurrence of atrial fibrillation among grown-up adults [29]. Similarly, Linberg and Karas studies have shown a connection between quite high levels of plasma adiponectin and heart failure, coronary heart disease, and even mortality [30, 31].

Moreover, Zhu et al. reported that in many chronic diseases, adiponectin causes pathogenesis due to its anti-inflammatory, insulin-sensitizing, and antioxidant effects. In the same way, recent studies also revealed that adiponectin is associated with an increased risk of 
cardiovascular disease and potential markers including atrial fibrillation [21].

Additionally, Shimano et al. revealed that cardiovascular diseases, including cardiac arrhythmia, are the most common condition in which plasma adiponectin levels were higher in chronic AF as compared to paroxysmal AF and controls. They have shown that adiponectin is correlated with carboxy-terminal telopeptide of collagen I, and collagen metabolism marker but it is not correlated with type II procollagen-N-peptide. However, study did not report the adiponectin about fainting, syncope, ventricular arrhythmia, or sudden death [10]. Similarly, previous studies reported that adiponectin may be associated with mechanisms for pathogenetic factors for AF including atrial remodeling, autonomic dysfunction, and inflammation. Also, Ybarra et al. found that left atrial size was negatively associated with adiponectin which could prevent atrial interstitial fibrosis, and contrary atrial remodeling [32].

\section{Apelin}

Apelin is considered to be the adipokines, bioactive mediators, which are produced and secreted from adipose tissues. Tatemoto et al. firstly isolated Apelin from the bovine stomach in 1998 naming it after APJ endogenous ligand, a novel peptide, which has been recognized on human APJ orphan receptor. Apelin is synthesized as a preproprotein that is cleaved through $\mathrm{N}$-terminal proteolysis to generate many mature biologically active forms including apelin-12, apelin-13, apelin-16, apelin-17, and apelin-36. Furthermore, apelin may play role in the physiology and pathophysiology of the cardiovascular system, while it is highly expressed in vascular smooth muscle cells, cardiomyocytes, and endothelial cells. Apelin has high expression in the heart atrium and also has multiple functions within cardiovascular homeostasis affecting vascular tone, angiogenesis, body fluid homeostasis or acts as a positive inotropic factor [33].

Moreover, apelin plays a role in the pathophysiology of diabetes mellitus, obesity, and atherosclerosis that may affect many metabolic pathways, including carbohydrate metabolism, where the apelin or APJ system is interdependent with insulin [34]. Similarly, in vitro on an animal model, apelin influences the electrophysiological function of atrial myocytes and shortening the action potential [35]. Further, Szokodi et al. revealed that apelin-16 is an active form of apelin that increased mean arterial filling pressure, cardiac contractility in the isolated perfused rat heart through stimulation of $\mathrm{Ca}^{2+}$ influx, and activation of phospholipase $\mathrm{C}$ systems. The reduction of intra-atrial pressure may improve the physical characteristics of atria and decrease pulmonary vein ectopic electrical activity, thereby exerting potent vasodilator and positive inotropic activities leading to an increase in the conduction velocity and a decrease in the field potential duration in vitro neonatal cardiomyocytes-all of which have been proved to be important mechanisms underlying the pathogenesis and progression of AF. These protective effects of apelin may be the mechanisms involved in increased serum apelin at baseline, which may be used to predict favorable outcomes after Pulmonary vein isolation (PVI) procedures [36, 37].

Furthermore, Kim et al. study has shown that Apelin played role in angiogenesis, development of new blood vessels, and cardiac development that influences cardiovascular physiology by provoking the renin-angiotensinaldosterone system, changing blood pressure, cardiac inotropy, oxidative stress, myocardial fibrosis, and hypertrophy. On the other hand, APJ receptors involved directly regulate ventricular excitability, refractoriness, contractility, conduction in association with amplified cardiac peak sodium current and reduced recovery from inactivation. Interestingly, Apelin has a role in the regulation of atrial electrophysiology by 200 -fold immunoreactivity greater in atrial than ventricular tissue. The level of apelin is reduced in patients with lone AF as in supraventricular arrhythmias and apelin plasma levels predict atrial arrhythmia recurrence. Moreover, it might have benefits in treating atrial arrhythmias. Earlier, AF patients found to be linked to decreased levels of apelin which have oxidative stress as well as have high atrial NADPH (nicotinamide adenine dinucleotide phosphate) oxidase activity and oxidative stress, which has been linked to a decreased level of apelin [38].

\section{C1q/TNF-Related Protein 3 (CTRP3)}

Complement $\mathrm{C} 1 \mathrm{q}$ tumor necrosis factor-related protein 3 is also denoted as CTRP3, new adipokine as well as the cluster of active endocrine cytokines, which is secreted by adipocytes [39]. CTRP3 is homology with adiponectin, a newly discovered adipokine, which has played role in energy metabolism as well as cardiovascular function. CTRP3 has performed the regulatory function of endocrine secretion, immune and inflammatory responses, glycolipid metabolism, vascular calcification, ventricular remodeling, mitochondrial biosynthesis, and angiogenesis [40, 41, 42].

Similarly, Kourliouros and Shin have shown that epicardial adipose tissue has involved in atrial fibrosis and structural remodeling which is caused due to secretion of a variety of inflammatory factors as well as adipokines $[22,43]$.

CTRP3 and adiponectin are structurally similar while adiponectin is involved with AF through various inflammation factors. Furthermore, Shin et al. study has been conducted to explain the level of adiponectin in AF 
patients which were independently associated with adipose tissue and thickness of atrial septum that also independently linked to the volume of the left atrium and atrial remodeling found to be ultimately linked to adiponectin [43]. In addition, Hou et al. study also reported that CTRP3 is similar to adiponectin which has been identified to take part in myocardial remodeling with the functions of anti-apoptosis and antiinflammation [42].

Furthermore, Chen et al. study found that the plasma CTRP3 levels were significantly lower in the atrial fibrillation group as compared to the control group. Moreover, persistent AF patients have lower plasma CTRP3 concentrations than paroxysmal AF patients. It was speculated that plasma CTRP3 might be involved in the development of AF; however, the underlying mechanism is still unclear which needs further research [7].

\section{Chemerin}

Chemerin is produced in adipose tissue and liver, which is also known as tazarotene-induced gene 2 or retinoic acid receptor responder protein 2 . The severity of coronary atherosclerosis and the higher prevalence of coronary artery disease were linked to the circulating concentration of chemerin. Also, arterial stiffness and carotid artery plague instability were independently related to the higher concentration of chemerin. Also, higher risk of cardiovascular events led to higher concentration of chemerin. Consequently, the lower risk of Heart Failure and chemerin has been identified [44].

In addition, there was a significantly higher relationship between serum chemerin concentration with atrial fibrillation patients as compared to the healthy control group, and also in subgroup studies, higher serum chemerin concentration was present with permanent atrial fibrillation as compared to those with paroxysmal and persistent atrial fibrillation. Besides, persistent atrial fibrillation patients had significantly higher serum concentrations of chemerin as compared to paroxysmal AF subjects. Logistic regression analysis had shown the association of serum chemerin concentration with the presence of atrial fibrillation. In addition, Pearson correlation analysis reported a positive relation of serum concentrations with diastolic blood pressure, body mass index (BMI), systolic blood pressure, blood urea nitrogen, left atrial diameter, $\mathrm{C}$-reactive protein, triglycerides, low-density lipoprotein cholesterol (LDL-C), and creatinine. As a result, they showed an association of serum chemerin concentration with atrial remodeling [45].

\section{Omentin-1}

Omentin-1 is a novel adipokine, expressed in omental adipose tissue, is also newly identified as $34 \mathrm{KDa}$ adipokine called intelectin-1 and is present in plasma abundantly. There are many physiological processes in which omentin-1 plays role in insulin action, inflammatory response, and cardiovascular function. Similarly, many studies have reported that omentin-1 in human endothelial cells inhibit tumor necrosis factor-induced vascular inflammation and also might change insulin sensitivity. On the contrary, one of the recent studies has revealed that omentin- 1 also has played a protective role against vascular calcification. However, clinical studies have demonstrated that obesity and insulin resistance were inversely correlated with omentin-1 levels. Furthermore, Tao et al. study has reported that AF development and atrial structural remodeling were inversely correlated with the serum level of omentin-1 [46], while the exact mechanism is still unknown that explains how omentin-1 regulates atrial fibrosis. However, a study was conducted to analyze epicardial adipose tissue (EAT) structure, and transforming growth factor beta 1 in epicardial adipose tissue and right atrial appendages. They investigated the expression levels of omentin-1 also explained the downregulation of omentin-1 in patients with $\mathrm{AF}$ and explore the roles of omentin-1 in atrial fibrosis [47].

Omentin-1 has been negatively correlated with heart failure and hypertension and also has a role in antiinflammatory effects. Otherwise, chemerin and resistin could be associated with AF by inflammatory pathways including thrombogenesis, structural atrial remodeling, and electrical atrial remodeling. Chemerin and resistin both were increased; on the other hand, omentin-1 concentration was decreased in the AF group. However, it was not statistical significant [48-50].

\section{Interleukin-6}

Interleukin- 6 is a group of cytokines that are small proteins for cell signaling and plays a role as an anti-inflammatory myokine which are released from myocytes, a pro-inflammatory cytokine, and as a natural inflammatory response. It produces a response to tissue damage and infections in the body. Many cells produce this cytokine such as mast cells, vascular endothelial cells, dendritic cells, fibroblasts, $\mathrm{T}$ and $\mathrm{B}$ cells, mesangial cells, and keratinocytes. Moreover, interleukin- 6 is coded by the IL6 gene in humans [51-53].

Additionally, IL-6 is known as a remodeling biomarker because changing concentration of interleukin- 6 was linked with modification of the cardiac extracellular matrix and cardiac dysfunction in which IL-6 directly affects cell-to-cell communication between cardiac myocytes and fibroblasts. IL- 6 is a self-determining inflammatory biomarker that gives opposing consequences in heart failure patients [54]. Furthermore, elevated circulating level of interleukin- 6 has been reported in several studies that promote the development of myocardial 
damage, dysfunction in congestive heart failure, allograft rejection, the severity of left ventricular dysfunction, left ventricular assist device conditions, myocarditis, and cardiomyopathy [55].

Also, Wu et al. reported, in a recent meta-analysis in the general population, a greater risk of AF linked to a higher blood level of IL-6. However, AF recurrence risks were increased and associated with elevated serum IL-6 level, after electrical cardioversion and catheter ablation [56].

Further, Conway et al. revealed that stroke, even death, was independently related to elevated serum IL- 6 levels. Additionally, another study demonstrated that independent association of serum IL-6 levels with permanent/ paroxysmal AF patients resulted in adverse events and mortality [57]. Then, Marcus et al. further reported that AF patients with verse without previous AF episodes, serum CRP and IL-6 levels were similar, but when the blood samples were taken during AF, the level was noticed to be significantly increased [58]. Also, Lazzerini et al. reported that increased risk of atrial fibrillation has been observed during active inflammatory processes caused by changes in systemic inflammatory activation via elevation level of interleukin-6 and downregulation cardiac connexins. In the end, rapidly induces atrial electrical remodeling [59].

\section{Leptin}

In 1994, leptin was first identified and cloned. It is an adipokine and a product of the human leptin gene of 167-amino-acid that is secreted and synthesized in white adipose cells and positively correlated to the amount of body fat [60-62]. Also, Leptin is produced in the placenta in pregnant women, cardiomyocytes, and vascular smooth muscle cells. Function leptin receptor is found in the hypothalamus but also found in other organs of the body like liver, heart, and brain vasculature, endothelium of heart, smooth muscle pancreases, kidney, and myometrium [63].

Then, Lin et al. reported that LA electrophysiological characteristics and calcium homeostasis have been regulated by leptin that reduces the effect of isoproterenolinduced arrhythmogenesis and also has an advantageous role in the pathophysiology of atrial arrhythmogenesis [64]. In addition, Fukui et al. reported for the first time that leptin signaling was important for the progress of atrial fibrosis and atrial fibrillation evoked by angiotensin II [65]. Furthermore, Poetsch et al. revealed that adverse effects of leptin resistance and leptin signaling deficiency in the cardiovascular system are caused by the heart's response to a stress condition, increased fibrosis, enhanced inflammation, promoting cardiac remodeling due to impaired cardiac metabolism, and dysfunction of vascular [66].

Further, Wallace et al. studied that leptin concentrations were increased in patients with heart diseases including congestive heart failure and ischemic heart disease [67]. In addition, Sader et al. [68] demonstrated a novel association of leptin with ventricular hypertrophy, obesity, diabetes, and cardiovascular risks. Leptin is a cooperative manner with obesity, inflammation, hyperglycemia, and oxidative stress, which resulted in the development and progression of cardiovascular diseases [69].

Tsai and Jen-Pi's study [70] has shown a positive correlation between the elevation level of plasma leptin levels with the total number of stenotic coronary arteries in coronary artery disease patients. Further, Bobbert et al. study reported that dilated cardiomyopathy patients have a high level of leptin which is used as a biomarker for the development of heart failure [71].

Similarly, diabetic cardiomyopathy has no symptoms in the very early stages when it is progressed to result in reduced ejection fraction, left ventricular diastolic dysfunction, increased interstitial fibrosis, and left ventricular hypertrophy [72, 73]. Blood pressure and heart rate are increased by leptin mediation which may provoke an increase in myocardial workload by the sympathetic nervous system that results in cardiac hypertrophy [74].

\section{Tumor necrosis factor-alpha}

TNF- $\alpha$ is synthesized mainly by macrophages and monocytes. It is a glycoprotein peptide hormone that consisted of 185 amino acids. It is a pleiotropic pro-inflammatory molecule and its expression is up regulated in a variety of cardiovascular disease settings [75].

Further, TNF- $\alpha$ is a pro-inflammatory cytokine which means cell signaling protein and is used by the immune system. In the case of infection, macrophages and monocytes activate the TNF which leads to inflammation and injuries. Tumor necrosis factor-alpha has two receptors. TNFR1 expresses on most cell types which lead to apoptotic and pro-inflammatory signaling, while TNFR2 confines to epithelial, endothelial, and subsets of immune cells, and signaling is anti-inflammatory, encouraging cell proliferation, and wound healing [76-78].

Further, Chen et al. confirmed that atrial fibrosis has been caused due to the higher level of tumor necrosis factor-alpha in patients with permanent atrial fibrillation as compared to those in patients with sinus rhythm (SR) [79].

In addition, atrial fibrosis gives rise to the vulnerable tissue that substrates with slow conduction and also encourages the emergence of triggers that increases the probability of initiating re-entry. Finally, it causes the 
vulnerability to unidirectional conduction block. As a result, atrial structural remodeling has included myocyte hypertrophy, apoptosis, fibroblast proliferation, necrosis, excess production of extracellular matrix, and autophagy that results in fibrosis. Similarly, fibrosis results in atrial fibrillation progression which leads to an AF permanent type that promotes the structural remodeling caused by the long-term positive feedback loop that contributes to the progression of AF permanent type [80, 81].

Likewise, Qu et al. study reported that there has been a higher activity of NF- $\mathrm{K}$ B (nuclear factor kappa light chain enhancer of activated B cells) that elevated concentration of TNF- $\alpha$ with the valvular disease in patients. The study also showed that the pathogenesis increased by more fibrosis in right atrial tissues and severe lymphomonocyte infiltration [82].

Also, in atrial fibrillation, the tumor necrosis factoralpha is a good prognostic biomarker. The circulating TNF- $\alpha$ level has shown many clinical pathogeneses in AF by ST-segment elevation myocardial infarction, left ventricular reverse remodeling after cardiac resynchronization therapy, increased severity of progression, and cardiac death in patients who have congestive heart failure. The independent predictors of AF have the elevated level of soluble CD40 and receptor activator of nuclear factor- $\mathrm{k}$ B ligand (RANKL). Also, they were ligand to TNF- $\alpha$ superfamily [83-87].

Further, the gap remodeling and ion channel remodeling were caused due to atrial electrical remodeling and also included by constitutive acetylcholine-regulated $\mathrm{K}$ current, downregulation of L-type $\mathrm{Ca}{ }^{2+}$ current, and upregulation of rectifier background $\mathrm{K}$ current. The cardiomyocytes electrically were associated with the distribution of the gap junction connexin hemichannels as well as abnormal expression. The triggering mechanism of developing and maintaining AF was abnormal $\mathrm{Ca}^{2+}$ handling and intracellular $\mathrm{Ca}^{2+}$ overload [88].

In addition, atrial fibrillation is related to inflammation, early stage of inflammation, and tumor necrosis factor-alpha which is one of the pleiotropic pro-inflammatory upstream cytokines. These cytokines were related to several cardiovascular diseases such as heart failure, myocarditis, and coronary artery disease. Also, elevated tumor necrosis factor-alpha level has been found in atrial fibrillation patients. The electrical and structural remodeling of atrial tissue was caused due to inflammation. Moreover, the calcium accumulates within the atrial myocytes that induced cell apoptosis caused by fibrillating atria. Loss of atrial myocytes was replaced by fibrosis scar that contributes to the abnormal electrical conduction and spreading. The aberrant activity of atria could trigger a low-grade inflammatory response [89].

\section{Resistin}

Resistin is derived from Adipose tissue that assisted to perform an endocrine function, which is also identified as an adipose tissue-specific secretory factor (ADSF) and C/EBP-epsilon-regulated myeloid-specific secreted cysteine-rich protein (XCP1). Also, resistin is a cysteinerich peptide hormone and is encoded in humans at the RETN gene [90]. Immune and epithelial cells of primates, dogs, and pigs secret the resistin, and resistin itself secrets from adipose tissue of rodents. Moreover, in humans, the length of resistin pre-peptide is 108 amino acids residues with a molecular weight is $\sim 12.5 \mathrm{kDa}$ [91].

Similarly, resistin affects the endocrine system and plays a vital role in the inflammatory response to external as well as internal factors [92]. In addition, the fatty infiltration of the atrial wall has been caused due to the presence of adipocytes in the left atrium, even in obese patients. It might be the center of the interaction of adipocytes with the cardiac conduction system [93].

Furthermore, the presence of resistin in adipocytes could mediate the paracrine action of adipocytes and causes local inflammation through pro-inflammatory and inflammatory cytokines in the myocardial cells which results in dysfunction of the cell membrane and necrosis. Similarly, adipose tissue comes into contact with epicardial coronary arteries. Chronic local inflammation might also affect the development of fibrous tissue and cause coagulation disorders of the atrial endocardium. In diabetes mellitus, especially obese patients have elevated resistin and have regulated blood glucose concentration when it is maintained for a long time. This mechanism could be considered as systemic action and local action of resistin in the atrial myocardium which is linked to Paroxysmal AF, in this case, arrhythmia persists for a long time $[94,95]$.

Moreover, resistin is the substance that is involved in immune response, protein of inflammation, and in the action of left ventricular remodeling mechanism. In Paroxysmal AF patients, resistin level might be increased in the blood of patients, if other cardiovascular diseases have co-occurred [96, 97].

Additionally, many researchers have tried to link the increased concentration of resistin in patients with CVD, heart failure, and left ventricular dysfunction. The secretion of resistin by monocytes stimulates the secretion of inflammatory cytokines due to the endothelium and macrophages which resulted inconsequential in the initiation of fibroblasts, and the replacement of the gap formed between the myocytes and location of the dead fibrous cell caused by fibrous tissue. Then, various studies have reported that resistin has been associated with the human body immune response and chronic left 
ventricular myocardial damage resulting in left ventricular dysfunction [98].

\section{Interleukin-10}

Interleukin-10 is an anti-inflammatory cytokine and important immunoregulatory cytokine. It is also known as the human cytokine synthesis inhibitory factor (CSIF). Interleukin-10 is encoded by the interleukin-10 gene and located on chromosome 1 [99]. It is secreted by monocytes or M2 macrophages. IL-10 helps in many biological processes that regulate the differentiation and production of many immune cells such as mast cells, antigenpresenting cells, natural killer cells, $\mathrm{T}$ cells, granulocytes, and B cells. Various studies have shown that IL-10 has the main influence on autoimmune, inflammatory, and malignant diseases [100].

The estrogen replacement and atherosclerosis (ERA) trial study had been explained the high levels of interleukin-10 linked with upcoming danger for cardiovascular actions in post-menopausal women with recognized coronary atherosclerosis [101]. Another study explained baseline interleukin-10 level was not related to the risk of the cardiovascular event without any clinical heart disease, so it is a poor indicator of subclinical coronary atherosclerosis [102].

Interleukin-10 is a multifunctional anti-inflammatory cytokine. IL-10 plays a harmful role in causing cardiovascular disease, kidney disease, and chronic infection. A study has shown a strong link between the risk of developing atrial fibrillation and IL-10-592A/C polymorphism [103].

\section{Conclusion}

In conclusion, adipokines play a significant role in the development and progress of Atrial Fibrillation. Also, there are major adipokines such as adiponectin, apelin, C1q/TNF-Related Protein 3 (CTRP3), Chemerin, Omentin-1, interleukin-6, Leptin, TNF- $\alpha$, resistin, and interleukin-10, which played their pathophysiological role in atrial fibrillation by causing cardiac hypertrophy, increasing the cardiac contractility and action potential duration, atrial fibrosis, electrical and structural remodeling of atrial tissue.

\footnotetext{
Abbreviations

AF: Atrial fibrillation; CTRP3: C1q/TNF-Related Protein 3; CVD: Cardiovascular disease; CRP: C-reactive protein; EAT: Epicardial adipose tissue; LA: Left atrial; NADPH: Nicotinamide adenine dinucleotide phosphate; TNF-a: Tumor necrosis factor-alpha; RANKL: Receptor activator of nuclear factor-k B ligand; IL-6: Interleukin-6; IL-10: Interleukin-10; ECM: Excessive accumulation of extracellular matrix; HDL: High density lipoprotein; MetS: Metabolic syndrome.
}

Authors' contributions

SRM carried out the study design and data collection. SR wrote the manuscript. All authors read and approved the final manuscript. SR gave the editing services of the manuscript.

\section{Funding}

No funding was received. It was self-funded.

Availability of data and materials

Not applicable.

\section{Declarations}

Ethics approval and consent to participate

Not applicable.

\section{Consent for publication}

Not applicable.

\section{Competing interests}

The authors declare that they have no competing interests.

\section{Author details}

${ }^{1}$ Lahore College for Women University, Near Wapda Flats, Jail Rd, Jubilee Town, Lahore 54000, Punjab, Pakistan. ${ }^{2}$ Forman Christian College (A Chartered University), Zahoor Elahi Rd, Gulberg III, Lahore 54600, Punjab, Pakistan.

Received: 19 June 2021 Accepted: 7 September 2021

Published online: 03 November 2021

\section{References}

1. Conde J, Scotece M, Gómez R, López V, Gómez-Reino JJ, Lago F, Gualillo O. Adipokines: biofactors from white adipose tissue. A complex hub among inflammation, metabolism, and immunity. BioFactors. 2011;37(6):413-20.

2. Lehr S, Hartwig S, Sell H. Adipokines: a treasure trove for the discovery of biomarkers for metabolic disorders. PROTEOMICS Clin Appl. 2012;6(1-2):91-101.

3. Lemoine AY, Ledoux S, Larger E. Adipose tissue angiogenesis in obesity. Thromb Haemost. 2013;110(10):661-9.

4. Pereira SS, Alvarez-Leite JI. Adipokines: biological functions and metabolically healthy obese profile. J Recep Ligand Channel Res. 2014;7:15-25.

5. Chugh SS, Roth GA, Gillum RF, Mensah GA. Global burden of atrial fibrillation in developed and developing nations. Glob Heart. 2014;9(1):113-9.

6. Iwasaki YK, Nishida K, Kato T, Nattel S. Atrial fibrillation pathophysiology: implications for management. Circulation. 2011;124(20):2264-74.

7. Chen L, Liu S, Xu W, Zhang Y, Bai J, Li L, Cui M, Sun L. Association of Plasma C1q/TNF-Related Protein 3 (CTRP3) in patients with atrial fibrillation. Mediators of Inflammation. 2020;2020.

8. Lin YK, Chen YC, Chen JH, Chen SA, Chen YJ. Adipocytes modulate the electrophysiology of atrial myocytes: implications in obesity-induced atrial fibrillation. Basic Res Cardiol. 2012;107(5):1-1.

9. Velliou M, Sanidas E, Papadopoulos D, Iliopoulos D, Mantzourani M, Toutouzas K, Barbetseas J. Adipokines and atrial fibrillation: The important role of apelin. Hellenic J Cardiol HJC Hellenike kardiologike epitheorese. 2020;62:S1109-9666.

10. Shimano M, Shibata R, Tsuji Y, Kamiya H, Uchikawa T, Harata S, Muto M, Ouchi N, Inden Y, Murohara T. Circulating adiponectin levels in patients with atrial fibrillation. Circ J. 2008;72(7):1120-4.

11. Lin YK, Chen YC, Chang SL, Lin YJ, Chen JH, Yeh YH, Chen SA, Chen YJ. Heart failure epicardial fat increases atrial arrhythmogenesis. Int J Cardiol. 2013;167(5):1979-83.

12. Maeda K, Okubo K, Shimomura I, Funahashi T, Matsuzawa Y, Matsubara K. cDNA cloning and expression of a novel adipose specific 
collagen-like factor, apM1 (AdiPoseMost abundant Gene transcript 1). Biochem Biophys Res Commun. 1996;221(2):286-9.

13. Chen J, Tan B, Karteris E, Zervou S, Digby J, Hillhouse EW, Vatish M, Randeva HS. Secretion of adiponectin by human placenta: differential modulation of adiponectin and its receptors by cytokines. Diabetologia. 2006;49(6):1292-302.

14. Martinez-Huenchullan SF, Tam CS, Ban LA, Ehrenfeld-Slater P, Mclennan SV, Twigg SM. Skeletal muscle adiponectin induction in obesity and exercise. Metabolism. 2020;102:154008.

15. Esmaili S, Hemmati M, Karamian M. Physiological role of adiponectin in different tissues: a review. Arch Physiol Biochem. 2020;126(1):67-73.

16. Lara-Castro C, Fu Y, Chung BH, Garvey WT. Adiponectin and the metabolic syndrome: mechanisms mediating risk for metabolic and cardiovascular disease. Curr Opin Lipidol. 2007;18(3):263-70.

17. Kadowaki T, Yamauchi T, Kubota N, Hara K, Ueki K, Tobe K. Adiponectin and adiponectin receptors in insulin resistance, diabetes, and the metabolic syndrome. J Clin Investig. 2006;1 16(7):1784-92.

18. Nattel S, Harada M. Atrial remodeling and atrial fibrillation: recent advances and translational perspectives. J Am Coll Cardiol. 2014:63(22):2335-45.

19. Hu YF, Chen YJ, Lin YJ, Chen SA. Inflammation and the pathogenesis of atrial fibrillation. Nat Rev Cardiol. 2015;12(4):230-43.

20. Chen PS, Chen LS, Fishbein MC, Lin SF, Nattel S. Role of the autonomic nervous system in atrial fibrillation: pathophysiology and therapy. Circ Res. 2014;114(9):1500-15.

21. Zhu T, Wang Z, Wang S, Hu W, Chen H, Xie J, Wang M, Ma K, Jiang H. Association between serum adiponectin and atrial fibrillation: a casecontrol study stratified by age and gender. Cardiol Res Pract. 2021;2021.

22. Kourliouros A, Karastergiou K, Nowell J, Gukop P, Tavakkoli Hosseini M, Valencia O, Mohamed Ali V, Jahangiri M. Protective effect of epicardial adiponectin on atrial fibrillation following cardiac surgery. Eur J Cardiothorac Surg. 2011;39(2):228-32.

23. Kusayama T, Furusho H, Kashiwagi H, Kato T, Murai H, Usui S, Kaneko S, Takamura M. Inflammation of left atrial epicardial adipose tissue is associated with paroxysmal atrial fibrillation. J Cardiol. 2016;68(5):406-11.

24. Schnabel RB, Larson MG, Yamamoto JF, Kathiresan S, Rong J, Levy D, Keaney JF Jr, Wang TJ, Vasan RS, Benjamin EJ. Relation of multiple inflammatory biomarkers to incident atrial fibrillation. Am J Cardiol. 2009;104(1):92-6.

25. Malavazos AE, Ermetici F, Coman C, Corsi MM, Morricone L, Ambrosi B. Influence of epicardial adipose tissue and adipocytokine levels on cardiac abnormalities in visceral obesity. Int J Cardiol. 2007:121(1):132-4.

26. lacobellis G, Corradi D, Sharma AM. Epicardial adipose tissue: anatomic, biomolecular and clinical relationships with the heart. Nat Clin Pract Cardiovasc Med. 2005;2(10):536-43.

27. Frustaci A, Chimenti C, Bellocci F, Morgante E, Russo MA, Maseri A. Histological substrate of atrial biopsies in patients with lone atrial fibrillation. Circulation. 1997;96(4):1180-4.

28. Bilovol O, Shaposhnikova Y, Ilchenko I, Shalimova A. Relationship between peculiarities of atrial fibrillation, body mass index and adipokines levels. Vessel Plus. 2017;1:196-201.

29. Macheret F, Bartz TM, Djousse L, Ix JH, Mukamal KJ, Zieman SJ, Siscovick DS, Tracy RP, Heckbert SR, Psaty BM, Kizer JR. Higher circulating adiponectin levels are associated with increased risk of atrial fibrillation in older adults. Heart. 2015;101(17):1368-74.

30. Lindberg S, Pedersen SH, Møgelvang R, Bjerre M, Frystyk J, Flyvbjerg A, Galatius $S$, Jensen JS. Usefulness of adiponectin as a predictor of all-cause mortality in patients with ST-segment elevation myocardial infarction treated with primary percutaneous coronary intervention. Am J Cardiol. 2012;109(4):492-6.

31. Karas MG, Benkeser D, Arnold AM, Bartz TM, Djousse L, Mukamal KJ, Ix $\mathrm{JH}$, Zieman SJ, Siscovick DS, Tracy RP, Mantzoros CS. Relations of plasma total and high-molecular-weight adiponectin to new-onset heart failure in adults $\geq 65$ years of age (from the Cardiovascular Health study). Am J Cardiol. 2014;113(2):328-34.

32. Ybarra J, Resmini E, Planas F, Navarro-López F, Webb S, Pou JM, Santos A, Ballesta-López C. Relationship between adiponectin and left atrium size in uncomplicated obese patients: adiponectin, a link between fat and heart. Obes Surg. 2009;19(9):1324-32.

33. Tatemoto K, Hosoya M, Habata Y, Fujii R, Kakegawa T, Zou MX, Kawamata Y, Fukusumi S, Hinuma S, Kitada C, Kurokawa T. Isolation and characterization of a novel endogenous peptide ligand for the human APJ receptor. Biochem Biophys Res Commun. 1998;251(2):471-6.

34. Boucher J, Masri B, Daviaud D, Gesta S, Guigné C, Mazzucotelli A, Castan-Laurell I, Tack I, Knibiehler B, Carpéné C, Audigier Y. Apelin, a newly identified adipokine up-regulated by insulin and obesity. Endocrinology. 2005;146(4):1764-71.

35. Cheng CC, Weerateerangkul P, Lu YY, Chen YC, Lin YK, Chen SA, Chen YJ. Apelin regulates the electrophysiological characteristics of atrial myocytes. Eur J Clin Invest. 2013:43(1):34-40.

36. Kalea AZ, Batlle D. Apelin and ACE2 in cardiovascular disease. Curr Opin Investig Drugs. 2010;11(3):273-82.

37. Szokodi I, Tavi P, Földes G, Voutilainen-Myllylä S, Ilves M, Tokola H, Pikkarainen S, Piuhola J, Rysä J, Tóth M, Ruskoaho H. Apelin, the novel endogenous ligand of the orphan receptor APJ, regulates cardiac contractility. Circ Res. 2002;91(5):434-40.

38. Kim YM, Lakin R, Zhang H, Liu J, Sachedina A, Singh M, Wilson E, Perez $M$, Verma S, Quertermous T, Olgin J. Apelin increases atrial conduction velocity, refractoriness, and prevents inducibility of atrial fibrillation. JCl Insight. 2020;5(17).

39. Hofmann C, Chen N, Obermeier F, Paul G, Büchler C, Kopp A, Falk W, Schäffler A. C1q/TNF-related protein-3 (CTRP-3) is secreted by visceral adipose tissue and exerts antiinflammatory and antifibrotic effects in primary human colonic fibroblasts. Inflamm Bowel Dis. 2011;17(12):2462-71.

40. Wölfing B, Buechler C, Weigert J, Neumeier M, Aslanidis C, Schöelmerich J, Schäffler A. Effects of the new C1q/TNF-related protein (CTRP-3) "cartonectin" on the adipocytic secretion of adipokines. Obesity. 2008;16(7):1481-6.

41. Maeda T, Wakisaka S. CTRP3/cartducin is induced by transforming growth factor- $\beta 1$ and promotes vascular smooth muscle cell proliferation. Cell Biol Int. 2010;34(3):261-6.

42. Hou M, Liu J, Liu F, Liu K, Yu B. C1q tumor necrosis factor-related protein-3 protects mesenchymal stem cells against hypoxia-and serum deprivation-induced apoptosis through the phosphoinositide 3-kinase/ Akt pathway. Int J Mol Med. 2014;33(1):97-104.

43. Shin SY, Yong HS, Lim HE, Na JO, Choi CU, Choi Jl, Kim SH, Kim JW, Kim EJ, Park SW. Total and interatrial epicardial adipose tissues are independently associated with left atrial remodeling in patients with atrial fibrillation. J Cardiovasc Electrophysiol. 2011;22(6):647-55.

44. Menzel J, di Giuseppe R, Biemann R, Wittenbecher C, Aleksandrova K, Eichelmann F, Fritsche A, Schulze MB, Boeing H, Isermann B, Weikert C. Association between chemerin, omentin-1 and risk of heart failure in the population-based EPIC-Potsdam study. Sci Rep. 2017;7(1):1-9.

45. Zhang $G$, Xiao M, Zhang L, Zhao Y, Yang Q. Association of serum chemerin concentrations with the presence of atrial fibrillation. Ann Clin Biochem. 2017:54(3):342-7.

46. Tao S, Huang YQ, Cai AP, Huang C, Zhang Y, Tang ST, Yu XJ, Zhou D, Tan $\mathrm{N}$, Feng YQ. Association of serum omentin-1 concentrations with the presence of atrial fibrillation. Med Sci Monit Int Med J Exp Clin Res. 2016;22:4749.

47. Chen Y, Liu F, Han F, Lv L, Tang CE, Xie Z, Luo F. Omentin-1 is associated with atrial fibrillation in patients with cardiac valve disease. BMC Cardiovasc Disord. 2020;20:1-2.

48. Velliou M, Papadopoulos D, Sanidas E, Zerva K, Tsakalis K, Vakrou S, Iliopoulos D, Mantzourani M, Perrea D, Barbetseas J. The role of apelin and visfatin in patients with atrial fibrillation. J Hypertens. 2019;37:e246.

49. Van de Voorde J, Pauwels B, Boydens C, Decaluwé K. Adipocytokines in relation to cardiovascular disease. Metabolism. 2013;62(11):1513-21.

50. Ermakov S, Azarbal F, Stefanick ML, LaMonte MJ, Li W, Tharp KM, Martin LW, Nassir R, Salmoirago-Blotcher E, Albert CM, Manson JE. The associations of leptin, adiponectin and resistin with incident atrial fibrillation in women. Heart. 2016;102(17):1354-62.

51. Ferguson-Smith AC, Chen YF, Newman MS, May LT, Sehgal PB, Ruddle $\mathrm{FH}$. Regional localization of the interferon- $32 \mathrm{~B}$-cell stimulatory factor $2 /$ hepatocyte stimulating factor gene to human chromosome 7p15-p21. Genomics. 1988;2(3):203-8.

52. Tanaka T, Narazaki M, Kishimoto T. IL-6 in inflammation, immunity, and disease. Cold Spring Harbor Perspectivas de la Biología. 2014;6(10):a016295.

53. Mauer J, Denson JL, Brüning JC. Versatile functions for IL-6 in metabolism and cancer. Trends Immunol. 2015;36(2):92-101. 
54. van Kimmenade RR, Januzzi JL Jr. Emerging biomarkers in heart failure. Clin Chem. 2012;58(1):127-38.

55. Kanda T, Takahashi T. Interleukin-6 and cardiovascular diseases. Jpn Heart J. 2004;45(2):183-93.

56. Wu SS, Liang QH, Liu Y, Cui RR, Yuan LQ, Liao EY. Omentin-1 stimulates human osteoblast proliferation through PI3K/Akt signal pathway. Int J Endocrinol 2013;2013.

57. Conway DS, Buggins P, Hughes E, Lip GY. Prognostic significance of raised plasma levels of interleukin- 6 and $C$-reactive protein in atrial fibrillation. Am Heart J. 2004;148(3):462-6.

58. Marcus GM, Smith LM, Ordovas K, Scheinman MM, Kim AM, Badhwar $\mathrm{N}$, Lee RJ, Tseng ZH, Lee BK, Olgin JE. Intracardiac and extracardiac markers of inflammation during atrial fibrillation. Heart Rhythm. 2010;7(2):149-54.

59. Lazzerini PE, Laghi-Pasini F, Acampa M, Srivastava U, Bertolozzi I, Giabbani B, Finizola F, Vanni F, Dokollari A, Natale M, Cevenini G. Systemic inflammation rapidly induces reversible atrial electrical remodeling: the role of interleukin-6-mediated changes in connexin expression. J Am Heart Assoc. 2019;8(16):e011006.

60. Considine RV, Sinha MK, Heiman ML, Kriauciunas A, Stephens TW, Nyce $M R$, et al. Serum immunoreactive-leptin concentrations in normalweight and obese humans. N Engl J Med. 1996;334(5):292-5.

61. Zhang Y, Proenca R, Maffei M, Barone M, Leopold L, Friedman JM. Positional cloning of the mouse obese gene and its human homologue. Nature. 1994;372(6505):425-32.

62. Koh KK, Park SM, Quon MJ. Leptin and cardiovascular disease: response to therapeutic interventions. Circulation. 2008:117(25):3238-49.

63. Ghantous CM, Azrak Z, Hanache S, Abou-Kheir W, Zeidan A. Differential role of leptin and adiponectin in cardiovascular system. Int J Endocrinol 2015;2015.

64. Lin YK, Chen YC, Huang JH, Lin YJ, Huang SS, Chen SA, Chen YJ. Leptin modulates electrophysiological characteristics and isoproterenol-induced arrhythmogenesis in atrial myocytes. J Biomed Sci. 2013;20(1):1-9.

65. Fukui A, Takahashi N, Nakada C, Masaki T, Kume O, Shinohara T, Teshima Y, Hara M, Saikawa T. Role of leptin signaling in the pathogenesis of angiotensin II-mediated atrial fibrosis and fibrillation. Circ Arrhythmia Electrophysiol. 2013;6(2):402-9.

66. Poetsch MS, Strano A, Guan K. Role of leptin in cardiovascular diseases. Front Endocrinol. 2020;11:354.

67. Wallace AM, MCMahon AD, Packard CJ, Kelly A, Shepherd J, Gaw A, Sattar N. Plasma leptin and the risk of cardiovascular disease in the west of Scotland coronary prevention study (WOSCOPS). Circulation. 2001;104(25):3052-6.

68. Sader S, Nian M, Liu P. Leptin: a novel link between obesity, diabetes, cardiovascular risk, and ventricular hypertrophy.

69. Packer M. Do sodium-glucose co-transporter-2 inhibitors prevent heart failure with a preserved ejection fraction by counterbalancing the effects of leptin? A novel hypothesis. Diabetes Obes Metab. 2018;20(6):1361-6.

70. Tsai JP, Wang JH, Chen ML, Yang CF, Chen YC, Hsu BG. Association of serum leptin levels with central arterial stiffness in coronary artery disease patients. BMC Cardiovasc Disord. 2016;16(1):1-7.

71. Bobbert P, Jenke A, Bobbert T, Kühl U, Rauch U, Lassner D, Scheibenbogen C, Poller W, Schultheiss HP, Skurk C. High leptin and resistin expression in chronic heart failure: adverse outcome in patients with dilated and inflammatory cardiomyopathy. Eur J Heart Fail. 2012;14(11):1265-75.

72. Jia G, Hill MA, Sowers JR. Diabetic cardiomyopathy: an update of mechanisms contributing to this clinical entity. Circ Res. 2018;122(4):624-38.

73. Lourenco AP, Leite-Moreira AF, Balligand JL, Bauersachs J, Dawson D, de Boer RA, de Windt LJ, Falcão-Pires I, Fontes-Carvalho R, Franz S, Giacca $M$. An integrative translational approach to study heart failure with preserved ejection fraction: a position paper from the Working Group on Myocardial Function of the European Society of Cardiology. Eur J Heart Fail. 2018;20(2):216-27.

74. Carlyle M, Jones OB, Kuo JJ, Hall JE. Chronic cardiovascular and renal actions of leptin: role of adrenergic activity. Hypertension. 2002;39(2):496-501.

75. Kany S, Vollrath JT, Relja B. Cytokines in inflammatory disease. Int J Mol Sci. 2019:20(23):6008.
76. Heir R, Stellwagen D. TNF-mediated homeostatic synaptic plasticity: from in vitro to in vivo models. Front Cell Neurosci. 2020;14.

77. Gough P, Myles IA. Tumor necrosis factor receptors: pleiotropic signaling complexes and their differential effects. Front Immunol. 2020;1 1.

78. Rolski F, Błyszczuk P. Complexity of TNF-a signaling in heart disease. J Clin Med. 2020;9(10):3267.

79. Chen YQ Wang L, Su X, Tao L, Chen XF. Calpain-I, calpastatin, caspase-3 and apoptosis in the human left atrium in rheumatic atrial fibrillation. Zhonghua Xin Xue Guan Bing Za Zhi. 2006;34(4):303-7.

80. Burstein B, Comtois P, Michael G, Nishida K, Villeneuve L, Yeh YH, Nattel S. Changes in connexin expression and the atrial fibrillation substrate in congestive heart failure. Circ Res. 2009;105(12):1213-22.

81. Nguyen TP, Qu Z, Weiss JN. Cardiac fibrosis and arrhythmogenesis: the road to repair is paved with perils. J Mol Cell Cardiol. 2014;70:83-91.

82. Qu YC, Du YM, Wu SL, Chen QX, Wu HL, Zhou SF. Activated nuclear factor-KB and increased tumor necrosis factor-a in atrial tissue of atrial fibrillation. Scand Cardiovasc J. 2009;43(5):292-7.

83. Paulus WJ, Tschöpe C. A novel paradigm for heart failure with preserved ejection fraction: comorbidities drive myocardial dysfunction and remodeling through coronary microvascular endothelial inflammation. J Am Coll Cardiol. 2013;62(4):263-71.

84. Rordorf R, Savastano S, Sanzo A, Spazzolini C, De Amici M, Camporotondo R, Ghio S, Vicentini A, Petracci B, De Regibus V, Taravelli E. Tumor necrosis factor-a predicts response to cardiac resynchronization therapy in patients with chronic heart failure. Circ J. 2014: CJ-14

85. Gonzalvez M, Ruiz-Ros JA, Perez-Paredes M, Lozano ML, Garcia- Almagro FJ, Martinez-Corbalan F, et al. Prognostic value of tumor necrosis factor-alpha in patients with ST-segment elevation acute myocardial infarction. Rev Esp Cardiol. 2007;60:1233-41.

86. Pan JP, Liu TY, Chiang SC, Lin YK, Chou CY, Chan WL, et al. The value of plasma levels of tumor necrosis factor-alpha and interleukin-6 in predicting the severity and prognosis in patients with congestive heart failure. J Chin Med Assoc. 2004;67:222-8.

87. Antoniades C, Van-Assche T, Shirodaria C, Diesch J, Antonopoulos AS, Lee J, Cunnington C, Tousoulis D, Stefanadis C, Casadei B, Taggart D. Preoperative $S C D 40 \mathrm{~L}$ levels predict risk of atrial fibrillation after off-pump coronary artery bypass graft surgery. Circulation. 2009;120(11_suppl_1):S170-6.

88. Chen MC, Chang HW, Wu CJ, Yang CH, Yu TH, Chen CJ, et al. Balance between plasma levels of tumor necrosis factor-alpha and interleukin-10 in rheumatic mitral stenosis. Cardiology. 2005;104:171-5.

89. Deng H, Xue YM, Zhan XZ, Liao HT, Guo HM, Wu SL. Role of tumor necrosis factor-alpha in the pathogenesis of atrial fibrillation. Chin Med J (Engl). 2011;124:1976-82.

90. Wang H, Chu WS, Hemphill C, Elbein SC. Human resistin gene: molecular scanning and evaluation of association with insulin sensitivity and type 2 diabetes in Caucasians. J Clin Endocrinol Metab. 2002;87(6):2520-4.

91. Lazar MA. Resistin-and obesity-associated metabolic diseases. Horm Metab Res. 2007;39(10):710-6.

92. Samanidis G, Gkogkos A, Bousounis S, Alexopoulos L, Perrea DN, Perreas K. Blood plasma resistin and atrial fibrillation in patients with cardiovascular disease. Cardiol Res. 2020;11(5):286-93.

93. Ermakov S, Azarbal F, Stefanick ML, LaMonte MJ, Li W, Tharp KM, Martin LW, et al. The associations of leptin, adiponectin and resistin with incident atrial fibrillation in women. Heart. 2016;102(17):1354-62.

94. Peller M, Kaplon-Cieslicka A, Rosiak M, Tyminska A, Ozieranski K, Eyileten $C$, et al. Are adipokines associated with atrial fibrillation in type 2 diabetes? Endokrynol Pol. 2020;71:34-41.

95. DeClercq V, Taylor C, Zahradka P. Adipose tissue: the link between obesity and cardiovascular disease. Cardiovasc Hematol Disord Drug Targets. 2008;8(3):228-37.

96. Calabro P, Golia E, Maddaloni V, Malvezzi M, Casillo B, Marotta C, Calabro R, et al. Adipose tissue-mediated inflammation: the missing link between obesity and cardiovascular disease? Intern Emerg Med. 2009:4(1):25-34.

97. Hogas S, Bilha SC, Branisteanu D, Hogas M, Gaipov A, Kanbay M, Covic A. Potential novel biomarkers of cardiovascular dysfunction and disease: cardiotrophin-1, adipokines and galectin-3. Arch Med Sci. 2017;13(4):897-913. 
98. Streb W, Mitrega K, Szymala M, Wozniak A, Podolecki T, Kalarus Z. The intracardiac concentrations of the $\mathrm{N}$-terminal-pro B-type natriuretic peptide (NT-proBNP) and the determinants of its secretion in patients with atrial fibrillation. Kardiol Pol. 2018;76(2):433-9.

99. Eskdale J, Kube D, Tesch H, Gallagher G. Mapping of the human IL10 gene and further characterization of the 5 'flanking sequence. Immunogenetics. 1997;46(2):120-8.

100. Asadullah K, Sterry W, Volk HD. Interleukin-10 therapy-review of a new approach. Pharmacol Rev. 2003:55(2):241-69.

101. Lakoski SG, Liu Y, Brosnihan KB, Herrington DM. Interleukin-10 concentration and coronary heart disease (CHD) event risk in the estrogen replacement and atherosclerosis (ERA) study. Atherosclerosis. 2008;197(1):443-7.

102. Goldwater D, Karlamangla A, Merkin SS, Watson K, Seeman T. Interleukin-10 as a predictor of major adverse cardiovascular events in a racially and ethnically diverse population: Multi-Ethnic Study of Atherosclerosis. Ann Epidemiol. 2019;30:9-14.

103. Zheng DD, Ji SN, Chen C, Deng XT, Su YM, Pan HY, Cai XX, Li XF, Zhu JH, Pan M. Association of Interleukin-10 promotor polymorphisms with atrial fibrillation in Han Chinese. Int J Clin Exp Med. 2014;7(11):4199.
Ready to submit your research? Choose BMC and benefit from:

- fast, convenient online submission

- thorough peer review by experienced researchers in your field

- rapid publication on acceptance

- support for research data, including large and complex data types

- gold Open Access which fosters wider collaboration and increased citations

- maximum visibility for your research: over $100 \mathrm{M}$ website views per year

At BMC, research is always in progress.

Learn more biomedcentral.com/submissions 